\title{
Quality Management in Supply Chain Based on ISO9000
}

\author{
Guangshu Chang \\ Zhengzhou Institute of Aeronautics, Zhengzhou 450015, China \\ E-mail: cgs30@163.com
}

The research is partially supported by Natural Science Foundation of China (70771102, 70572050), Aerospace Science Foundation of China (2007ZG55005), Important Science and Technology Project of Henan Province (072102240037), and Education Foundation of Henan Province (2008B630009).

\begin{abstract}
This paper discussed the application of the eight modern quality management principles of ISO9000 in supply chain quality management, namely customer focus, leadership, involvement of people, process management, system management, continual improvement, factual approach to decision making, and mutually beneficial supplier relationships.
\end{abstract}

Keywords: Supply Chain, Quality Management, ISO9000

\section{Introduction}

In nowadays, the series standards of ISO9000 are implementing in many industries, such as manufacturing, service, even administrative organizations. In the introduction of Quality Management System of ISO9000:2000, eight principles of quality management are proposed, namely customer focus, leadership, involvement of people, process management, system management, continual improvement, factual approach to decision making, and mutually beneficial supplier relationship [1]. The eight principles generalize the success experience of the advanced enterprises in the developed countries.

In supply chain circumstance, the emphasis of research and practice of quality management has transferred from enterprise focus to supply chain focus. Not only the high quality of product and service but also the high level of quality control of the whole supply chain system ensures the competition advance. Therefore, the establishment of quality management system of supply chain based on the management ideas of ISO9000 will promote the involvement of all the members and facilitate the implement of quality control of the whole supply chain system.

\section{Supply chain quality management based on ISO9000}

\subsection{Customer focus}

Customer focus is the core principle and idea of quality management because quality effort comes of customer's needs and ends with customer's acceptance. In supply chain circumstance, customer includes not only the end user but also many in-between users, such as suppliers, manufacturers, sellers, etc. Therefore, the core enterprise must pay attention to the needs and expectation of end users, and all the members of supply chain must pay attention to the needs and expectation of their backward users. The needs and expectation of end users should be deployed layer upon layer in the whole supply chain system. The end users will satisfy if all the member of supply chain can satisfy the needs of their backward users. Moreover, the operation efficiency of supply chain system can be improved through the satisfaction level of the end users. Here, some traditional tools of total quality management (TQM) are also effective. For example, we can use Quality Function Deployment (QFD) to understand the distinct and potential needs of users, use Fishbone Chart to investigate the factors affecting the satisfaction level of users and then use Pareto Chart to find out the key factors.

\subsection{Leadership}

The effective of quality management depend on the effective of leadership because quality effort can get actual effect only with the recognition and support of the leadership. In supply chain circumstance, the core enterprise play as the leadership since it establishes the development strategy and operation targets of supply chain affect the actual efficiency and effectiveness of the quality effort of all the other members. Therefore, the core enterprise must act as leadership to consider adequately the needs and expectation of the other members, establish a clear, realizable and coincident holistic target, and then lead and inspire the other members to strive jointly for the target. At the same time, the core enterprise should foster more leaders of TQM in each layer of supply chain and make them take their responsibility zealously.

\subsection{Involvement of people}

The exertion of enthusiasm and creativity of all the employees is the precondition of the actual effect of quality 
management. In supply chain circumstance, an up-and-coming excelsior work atmosphere should be established to inspire the enthusiasm and creativity of the employees of all the members. Each employee should understand his/her role and responsibility in the supply chain system, solve the problems forwardly as mastership, and learn the principles, skills and technologies of TQM and ISO9000. Here, we can foster the ethos of self-motion and self-knowledge in supply chain through 5S, i.e. seiri, seiton, seiso, seiketsu, and shitshke. Furthermore, we can make all the employees participate into supply chain quality management and strive for the satisfaction of users jointly through the establishment of cross function or cross enterprise QC teams.

\subsection{Process management}

The focus of modern quality view is the process quality management but not the product itself of traditional quality view. It is the requirement of the quality management system of ISO9004:2000 and the essential difference of modern and traditional quality view. In each step of supply chain, there are many correlative processes, such as procurement, logistics, production, inventory, selling, service, etc. These processes have their own independent objectives and programs. There are usually conflicts among the objectives and programs. Therefore, the processes and their mutual effects should be identified and managed to ensure the harmonious operation of supply chain. Then, all the processes, especially the key processes, can realize high quality, i.e. small variation, small waste, and more increment, through the total quality control in all the steps of supply chain.

\subsection{System management}

The application of system approach in quality management is to view the quality management system as a big system, identify and manage the sub-systems respectively. Then, the coordinated effect and mutual promotion among the sub-systems will make the whole effect more than the sum of the improvement of each sub-system [2]. In supply chain circumstance, enterprise should confirm the mutual dependence relationship among the processes in supply chain system, break the boundary among supply chain members, construct and integrate the processes. Then, many well operation sub-systems can be constructed to collocate the resources rationally among the sub-systems. Finally, the whole supply chain system, including supply, transport, production, distribution, inventory, etc., can realize the target and policy of quality through the optimal operation mode.

\subsection{Continual improvement}

Continual improvement is one of the focuses of modern quality research and practice. Enterprise must improve the quality of product and service continually and reduce the cost to make customer satisfactory. In supply chain circumstance, the pressure of continual improvement is more and more pressing because the market competition is more and more hard. Not only the core enterprise but also the other members, such as suppliers, sellers, and logistics providers, must improve their product and service respectively so as to construct the continual improvement of products and services all over the supply chain process. Then, the continual, stable and harmonious ability of quality assurance can be established. Furthermore, the core enterprise and other members must find the ways and practices improving performance in or out of supply chain through benchmarking to make the continual improvement speed fast than the one of rivals.

\subsection{Factual approach to decision making}

The sufficient and adequate data and information is the foundation of making effective decision. Up to now, many enterprises have began to collect and deal with all kinds of data and information by utilizing many advanced information technology, e.g., EDI, MRP II, ERP, POS, Intranet, Extranet, Internet, so as to provide foundation for making effective decision. In supply chain circumstance, enterprise should collect data and information of not only itself but also the other members of supply chain to record and analyze the current operation situation of each member. Therefore, the potential problems in any step of supply chain can be found duly according to the results of data analysis. Then, the corresponding correct and timely decision can be made to avoid or rectify the problem.

\subsection{Mutually beneficial supplier relationships}

The organization and its supplier are mutually dependent. Maintaining the mutually beneficial relationships between them can improve the ability of creating value both of them. In supply chain circumstance, the product quality is performed and ensured by all the members of supply chain because the production, selling and service must be performed by all the members [3]. Therefore, the task of supply chain quality management is not only to establish the product inspection system and comprehensive evaluation system of suppliers, but also to strengthen the mutual beneficial partner relationships with suppliers. The core enterprise must realize the following activities:

(1) Identify and select the main suppliers, reduce the scale of supply system, and realize small supply base management;

(2) Investigate the requirements of customers and develop new product jointly with suppliers; 
(3) Share information, technology, and resource with suppliers;

(4) Admit the improvement and achievement of suppliers;

(5) Take joint improving activities with suppliers;

(6) Ensure the conformity of quality system between core enterprise and the other members, including basic conformity (e.g. program files, technology specification, process interface) and advanced conformity (e.g. quality target, quality policy, and quality culture).

In fact, there is a new trend in the international practices of supply chain management. Namely, more and more large-scale enterprises have pay attention to the management and development of suppliers, e.g. providing capital, technology, human resource, equipment and training for suppliers, sending quality teams to help suppliers improve their processes, and sharing the yields of continual improvement with suppliers.

\section{Concluding remarks}

The series standards of ISO9000 are made for the standardization of quality management and quality assurance. Therefore, in supply chain circumstance, the implementation of ISO9000 is the basic assurance for an enterprise to provide acceptable product or service and improve the quality level in a certain supply chain. The application of ISO9000 in supply chain quality management will promote the improvement of operation efficiency and competition ability of the whole supply chain system.

\section{References}

Ma, S. and Tang, X. (2001). Characteristics \& Strategies of Quality Management in Supply Chain. Computer Integrated Manufacturing Systems, 9, 32-35. [In Chinese]

Trent, R.J. (2001). Applying TQM to SCM. Supply Chain Management Review, May/June, 70-77.

Xu, X., Zhang, W., and Ye, C. (2002). Enterprise Quality Management Based on Supply Chain. Industrial Engineering Journal, 5, 39-42. [In Chinese] 